\title{
Impact of cement type and abutment height on pull-off force of zirconia reinforced lithium silicate crowns on titanium implant stock abutments: an in vitro study
}

\author{
Lisa Müller ${ }^{1}$, Angelika Rauch ${ }^{2}$ (D), Daniel R. Reissmann ${ }^{3}$ (D) and Oliver Schierz ${ }^{2^{*}}$ (D)
}

\begin{abstract}
Background: Pull-off forces of cement-retained zirconia reinforced lithium silicate (ZLS) in implant-supported single crowns on stock titanium abutments with respect to abutment height and implant cement were evaluated and compared.

Methods: Pull-off force of ZLS crowns on stock titanium abutments was evaluated concerning dental cement and abutment height. A total sample size of 64 stock abutments with heights of $3 \mathrm{~mm}(n=32)$ and $5 \mathrm{~mm}(n=32)$ was used. The ZLS crowns were cemented with four different types of cement (one temporary, two semi-permanent, and one permanent). After cementation, water storage, and thermocycling each sample was subjected to a pull-off test using a universal testing machine.

Results: The temporary cement showed the least pull-off force regardless of abutment height ( $3 / 5 \mathrm{~mm}$ : means $6 \mathrm{~N} / 23 \mathrm{~N}$ ), followed by the semi-permanent methacrylate-infiltrated zinc oxide cement ( $28 \mathrm{~N} / 55 \mathrm{~N}$ ), the semi-permanent methacrylate-based cement (103 N/163 N), and the permanent resin composite cement (238 N/820 N). Results of all types of cement differed statistically significantly from each other $(p \leq .012)$. The type of implant cement has an impact on the pull-off force of ZLS crowns and titanium abutments.
\end{abstract}

Conclusions: Permanent cements present higher retention than semi-permanent ones, and temporary cements present the lowest values. The abutment height had a subordinate impact.

Keywords: Ceramics, Fixed dental prosthesis, Implant cement, Prosthetic dentistry, Provisional cement, Semipermanent cement, Abutment height, Zirconia reinforced lithium silicate (ZLS)

\section{Background}

In everyday clinical practice, implants have become a beneficial treatment, especially to replace single teeth and to restore function, esthetics, and patient satisfaction with the oral appearance. Due to modern developments

\footnotetext{
${ }^{*}$ Correspondence: oliver.schierz@medizin.uni-leipzig.de

2 Department of Prosthodontics and Materials Science, University

of Leipzig, Liebigstrasse 12,04107 Leipzig, Germany

Full list of author information is available at the end of the article
}

in interdisciplinary research on dental materials, implant prosthetics, and surgery, and more as well as increasing survival rates, the choice and popularity of dental implants among dentists and patients has increased [1]. However, debates about favored materials and techniques in implant prosthetics continue until today $[2,3]$.

The retrievability of implant-supported single crowns (iSC) and multi-unit fixed dental prostheses (iFDPs) is substantial for the maintenance of implants, complication management, and replacement of the prosthesis [4]. 
In general, restorations can be screw-retained, cementretained, or fixed with a combination of both [5]. Regarding the survival of the implant, no clinically relevant differences were described between the rates of cementor screw-retained iSCs during the first five years. Thus, both fixation methods can be recommended for implantsupported restorations [3]. In the presence of limited interocclusal space of $4 \mathrm{~mm}$, screw-retained structures are preferred [6]. Advantages of cement-retained iSCs are the provision of a more passive fit of the crown, as well as better esthetical and occlusal features [7]. Due to reduced costs and the simplicity of the procedure, $60 \%$ of German clinical practitioners prefer cementation on implant abutments $[5,8]$. In comparison to screw-retained crowns conventional cementation can avoid common technical complications such as screw loosening or mechanical damage of the implant components. Furthermore, no special devices are needed for the conventional approach and the procedures follow the same routine as for natural abutment teeth [7].

However, for the long-term success of dental prosthesis implant-related biological complications are important too. Biological complications refer to soft and hard tissue diseases. One of the main disadvantages of cemented crowns is the risk of undetected cement residue that could lead to inflammatory reactions and periimplant complications, like peri-implantitis, peri-implant mucositis, soft tissue hypertrophy, or recession up to bone loss and necessary deplantation [9]. Studies prove, that biological challenges are higher with cement-retention than screw-retained implant-supported fixed dentures $[10,11]$.

Dental cements can be classified as temporary, semipermanent, and permanent. Temporary cements have been developed for short-term fixation and intended debonding. Therefore, they are inherently weak and soluble in the oral environment [12]. For the cementation of iSCs and iFDPs, a class of semi-permanent cements has been developed that accomplishes a chemical bond between the abutment and the restoration $[13,14]$. These cements should be characterized by sufficient strength, which avoids unintentional decementation and provides reliable intended decementation when needed. That aspect showed to be tremendous progress in the development of dental cements [15-17]. Many authors and clinicians recommend temporary cementation to facilitate retrievability of iSCs and iFDPs without damage $[18,19]$.

Factors affecting cemented iSCs and iFDPs are similar to those on natural teeth and are characterized by type of luting agent, film thickness, the roughness of the bonding surface, taper, width, and height of the abutments $[13,15$, 20]. In situations of limited interocclusal space, shorter abutments are mandatory, even if the small height may become a limiting factor for clinical success. Therefore, an investigation on pull-off forces regarding different abutment heights and different types of implant cements can provide valuable information for clinicians.

The purpose of this study was to evaluate and compare pull-off force of cement-retained zirconia reinforced lithium silicate iSCs on stock titanium abutments with respect to abutment height and implant cement. Regarding the pull-off force, the null-hypothesis states that there is no significant difference in iSCs made from ZLS bonded with four different dental implant cements to stock titanium abutments. The secondary hypothesis states that there is no difference in pull-off force regarding the abutment height.

\section{Methods}

For sample size calculation, data from preliminary pulloff tests were used. A pull-off force difference of $50 \mathrm{~N}$ between both heights was assumed as clinically relevant. Estimating a standard deviation of $30 \mathrm{~N}$ and a power of 0.9 , calculations revealed a sample size of 8 per group (in total 64 samples when using four different cements and two different abutment heights) using a two-sample test (STATA 15.1 College Station, TX: StataCorp LLC).

A number of 24 stock titanium abutments (CAMLOG iSy $^{\circledR}$ Esthomic $^{\circledR}$ abutments, CAMLOG Vertriebs GmbH, Germany) were physically available for the testing process. The abutments were delivered with a pronounced chamfer and tapering of 7.5 degrees. Half of the abutments were customized manually to a height of $3 \mathrm{~mm}$ and the other was customized to a height of $5 \mathrm{~mm}$ by using a Red Milling Cutter (A. M. Edelingh $\mathrm{M}+\mathrm{W}$ Dental, Germany). A mold was designed and fabricated, with the help of which the implant analogs were embedded in polymer blocks (Paladur ${ }^{\circledR}$, Kulzer GmbH, Germany). Each stock abutment was screw-retained to the implant analog with $20 \mathrm{Ncm}$ torque with a manufacturer-supplied manual torque controller (CAMLOG Biotechnologies AG, Germany). After cleaning with isopropanol, screw access openings were filled with a temporary resin composite material (Telio CS, Ivoclar Vivadent AG, Liechtenstein). A gingival mask was handmade with addition-curing vulcanizing silicone (GumQuick, Dreve Dentamid GmbH, Germany) for digitization of the stock abutments (Omnicam, CEREC Premium SW 4.5, Dentsply Sirona Deutschland GmbH, Germany).

All shorted stock abutments were scanned and an associated individual iSC was designed as upper left second premolars using a form template (inLab SW 4.6.1, Dentsply Sirona Deutschland GmbH, Germany). A spacer of $120 \mu \mathrm{m}$ was set [21]. A number of 24 monolithic ceramic crowns made of zirconia reinforced lithium silicate (VITA SUPRINITY $^{\circledR}$, VITA Zahnfabrik H. Rauter GmbH 


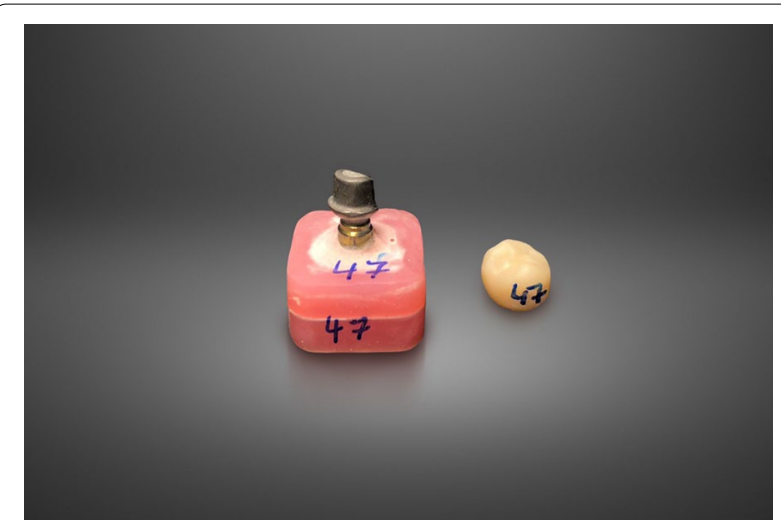

Fig. 1 Exemplary sample; implants analogue embedded in polymer blocks and milled and crystalized monolithic crown

\& Co. KG, Germany) were milled (inLab MCXL, Dentsply Sirona Deutschland GmbH, Germany) from ZLS blocks of $12 \times 14 \times 18 \mathrm{~mm}$.

The milled crowns were separated from the block and the lug was removed with a diamond-coated milling instrument. The iSCs were manually cleaned, air-dried, and crystallized according to the manufactures' instructions (Programat EP5000; Ivoclar Vivadent AG, USA). All crowns were polished, as recommended by the manufacturer. To reassociate the iSC to its abutment, each sample was numbered (Fig. 1). The bonding surfaces of the finished crowns were airborne abraded with $50 \mu \mathrm{m}$ $\mathrm{Al}_{2} \mathrm{O}_{3}$-particles at a pressure of one bar, duration of $10 \mathrm{~s}$, and a distance of $10 \mathrm{~mm}$ [22]. All restorations and abutments were purged with isopropanol (70\%) and air-dried immediately before cementation.

The cements (Table 1) were applied into the inner lumen of the restoration up to the cervical third of the crown and carefully placed on the corresponding stock abutment. Before the cementation with permanent resin composite cement, the inner surface of the crown was conditioned for $60 \mathrm{~s}$ (Monobond Plus, Ivoclar Vivadent $\mathrm{GmbH}$, Germany) and the surplus removed by air current. Subsequently, all restorations were placed on the stock abutment and kept in place for $10 \mathrm{~s}$. Thereafter, all samples were axially loaded with $50 \mathrm{~N}$ for about $10 \mathrm{~min}$ under room conditions $\left(21^{\circ} \mathrm{C}\right.$ and $50 \%$ humidity).

After $24 \mathrm{~h}$ water storage at $37{ }^{\circ} \mathrm{C}$, all samples were loaded with 37,500 thermal cycles (Thermocycler Haake DC 10, W 15, Thermo Haake GmbH, Germany), corresponding to a lifetime of approximately 4 years in vivo [23], making the study comparable to clinical short-term studies [5]. For thermocycling, two water baths were filled with $5{ }^{\circ} \mathrm{C}$ and $55{ }^{\circ} \mathrm{C}$ tempered, distilled water with a dwell time of $30 \mathrm{~s}$ and a transition time of $10 \mathrm{~s}$. Both temperature data correspond to the median value of the measured maximum and minimum temperatures in the oral cavity [23].

Afterwards, each sample was clamped into a custommade device setting (Fig. 2) (Zwick Roell Z010, Test X pert ${ }^{\circledR}$ II V2.2, ZwickRoell GmbH \& Co. KG, Germany).

The crowns were axially removed with a crosshead speed of $2 \mathrm{~mm} / \mathrm{min}$ and a preload of $4 \mathrm{~N}$. The Adhesive Remnant Index [24] was registered according to Table 2 immediately after the crown removal, to record the quantitative affinity of the cements for abutment and crown surfaces.

The available 24 stock abutments and belonging crowns of both heights were refurbished up to two times, so a total amount of 64 tests in both abutment heights could be performed. The intactness and complete purification of the inner and outer surface of crown and abutment were visually inspected with magnifying glasses (magnification 2.5). Every luting agent was tested eight times with

Table 1 Classification and main components of the used luting agents

\begin{tabular}{|c|c|c|c|c|}
\hline $\begin{array}{l}\text { Trading name } \\
\text { (abbreviation) }\end{array}$ & Type & Manufacturer & Classification & Main components \\
\hline $\begin{array}{l}\text { TempBond } \mathrm{NE}^{\circledR} \\
\text { (TBNE) }\end{array}$ & $\begin{array}{l}\text { Zinc oxide cement } \\
\text { (chemical curing) }\end{array}$ & KerrHawe SA, Swizerland & Temporary [17] & Zinc oxide, zinc acetate dihydrate \\
\hline $\begin{array}{l}\text { Harvard Implant }{ }^{\circledR} \\
(\mathrm{HI})\end{array}$ & $\begin{array}{l}\text { Methylacrylate-infiltrated } \\
\text { zinc oxide cement } \\
\text { (dual curing) }\end{array}$ & $\begin{array}{l}\text { Havard Dental Intl GmbH, } \\
\text { Germany }\end{array}$ & Semi-permanent & $\begin{array}{l}\text { Zinc oxide, multifunctional } \\
\text { methacrylates }\end{array}$ \\
\hline $\begin{array}{l}\text { Premier }^{\circledR} \text { Implant Cement } \\
(\mathrm{PI})\end{array}$ & $\begin{array}{l}\text { Methacrylate-based cement } \\
\text { (chemical curing) }\end{array}$ & $\begin{array}{l}\text { Premier }{ }^{\circledR} \text { Dental Products Com- } \\
\text { pany, Pennsylvania USA }\end{array}$ & Semi-permanent [17] & $\begin{array}{l}\text { Triethylenglycoldi-methacrylate, } \\
\text { fumed silica, 2-hydroxy-ethyl- } \\
\text { methacrylate, benzoyl peroxide, } \\
\text { resin }\end{array}$ \\
\hline $\begin{array}{l}\text { SpeedCEM }{ }^{\circledR} \text { Plus } \\
(\mathrm{SCP})\end{array}$ & $\begin{array}{l}\text { Composite cement } \\
\text { (self-adhesive, dual curing) }\end{array}$ & $\begin{array}{l}\text { Ivoclar Vivadent GmbH, } \\
\text { Germany }\end{array}$ & Permanent & $\begin{array}{l}\text { Triethylenglycoldi-methacrylate, } \\
\text { polyethylenglycoldi-meth- } \\
\text { acrylate, ytterbium trifluoride, } \\
\text { 10-methacryloyl-oxydecyldihy- } \\
\text { drogen-phosphat }\end{array}$ \\
\hline
\end{tabular}




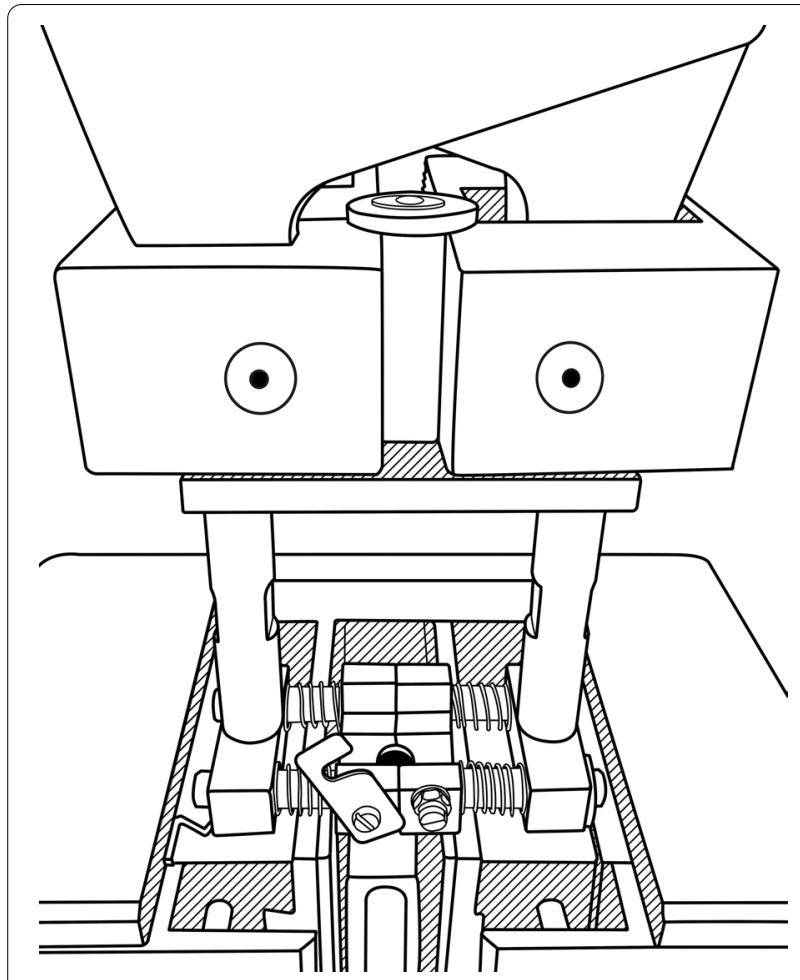

Fig. 2 Custom-made device setting in the universal testing machine, for measurement of the pull-off force

Table 2 Codes for visual, quantitative classification of the cement remnants on the abutments and in the crowns (modified Adhesive Remnant Index [24])

\begin{tabular}{ll}
\hline Codes & Interpretation \\
\hline 1 & Cement adheres completely to the abutment \\
2 & More than $50 \%$ of the cement adheres to the abutment \\
4 & More than $50 \%$ of the cement adheres in the crown \\
\hline
\end{tabular}

each abutment height. All 64 samples (Fig. 3) were processed in randomized order according to the flowchart.

Data were statistically analyzed with SPSS (V27.0.0.0, IBM Deutschland GmbH, Germany) applying one-way ANOVA to test whether there was a difference concerning the applied type of cement, and $t$-test to figure out differences regarding abutment height and the comparison between the 4 cements. To estimate the effect size, Cohen's $d$ was calculated and interpreted after Sawilowsky [25]. The results of the Adhesive Remnant Index were statistically evaluated by using the KruskalWallis-Test, and Mann-Whitney-U-Test was used to figure out differences regarding the different cements.

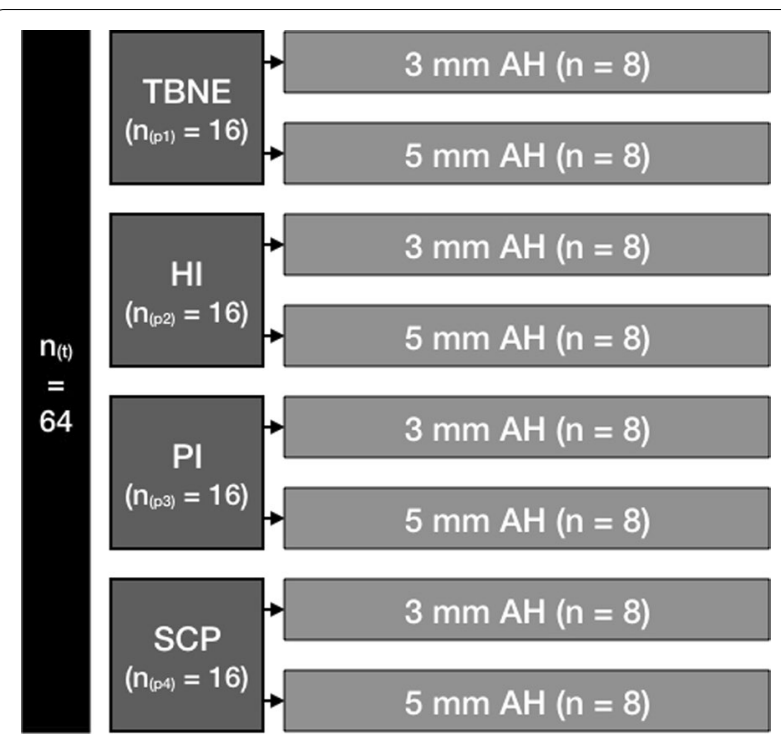

Fig. 3 Flowchart; TBNE $=$ TempBond $N E^{\circledR}$ a temporary zinc oxide-based cement, $\mathrm{HI}=$ Harvard Implant $^{\circledR}$ a semi-permanent methacrylate-infiltrated zinc oxide cement, $\mathrm{PI}=$ Premier $^{\circledR}$ Implant

Cement $^{\mathrm{TM}}$ a semi-permanent methacrylate-based cement, $\mathrm{SCP}=$ SpeedCEM ${ }^{\circledR}$ Plus a permanent composite cement, $\mathrm{AH}=$ abutment height

\section{Results}

The temporary zinc oxide-based cement (TBNE) showed the least mean pull-off force regardless of the abutment height $(3 \mathrm{~mm} / 5 \mathrm{~mm}$ : means $6 \mathrm{~N} / 23 \mathrm{~N})$, followed by the semi-permanent methacrylate-infiltrated zinc oxide cement $(\mathrm{HI})(28 \mathrm{~N} / 55 \mathrm{~N})$, the semi-permanent methacrylate-based cement $(\mathrm{PI})(103 \mathrm{~N} / 163 \mathrm{~N})$ and the permanent composite cement (SCP) $(238 \mathrm{~N} / 820 \mathrm{~N})$. In the temporary cement group, more than half of the crowns debonded spontaneously. Samples bonded with the two strongest implant cements (PI and SCP) showed damages of the crowns while removal in both abutment heights (PI: 12.5\%; SCP: 25.0\%).

The statistical analysis revealed a significant difference and a huge effect size $(d>2.0)$ for abutment height when using SCP and HI. There were no statistically significant differences between the pull-off forces regarding the abutment height in the groups of PI and TBNE (Table 3). Moreover, statistically significant differences in pull-off forces between all cements and an abutment height of $3 \mathrm{~mm}$ and $5 \mathrm{~mm}$ were detected, as well as very large to huge effect sizes (Tables 4,5). Solely the pairing of TBNE and $\mathrm{HI}$ on $5 \mathrm{~mm}$ abutment height presented no statistically significant differences in pull-off force (Table 5) and small effect size $(d>0.2)$.

Table 6 depicts the residues of the remnant cement on an abutment and/or crown. The temporary cement left most of the residue on the titanium surface of the 
Table 3 Pull-off force with respect to cement and abutment height

\begin{tabular}{|c|c|c|c|c|c|c|}
\hline \multirow[t]{2}{*}{ Cement } & \multicolumn{2}{|c|}{$3 \mathrm{~mm}$ abutment height } & \multicolumn{2}{|c|}{$5 \mathrm{~mm}$ abutment height } & \multirow{2}{*}{$\begin{array}{l}\text { Statistical } \\
\text { significance }\end{array}$} & \multirow[t]{2}{*}{ Effect size } \\
\hline & Mean (SD) in $\mathrm{N}$ & Range in $\mathrm{N}$ & Mean (SD) in $\mathrm{N}$ & Range in $\mathbf{N}$ & & \\
\hline TBNE & $6(12)^{6}$ & $0-27$ & $23(21)^{3}$ & $0-54$ & $p=0.074$ & 0.99 \\
\hline $\mathrm{HI}$ & $28(6)$ & $22-37$ & $55(39)$ & $8-102$ & $p<0.001^{*}$ & 0.97 \\
\hline PI & $103(40)^{\# 1}$ & $49-180$ & $163(96)^{\# 1}$ & $71-310$ & $p=0.132$ & 0.83 \\
\hline SCP & $238(131)^{\# 2}$ & $66-525$ & $820(180)^{\# 2}$ & $550-1170$ & $p<0.001^{*}$ & 3.70 \\
\hline
\end{tabular}

(a) Asterisks (*) mark statistically significant differences

(b) $\mathrm{X}^{\# \mathrm{n}}$ marks the count of crown fractures

(c) $X^{n}$ marks the count of premature debonding

Table 4 Probability of statistically significant differences and effect size of cement pairings $3 \mathrm{~mm}$ abutment height

\begin{tabular}{lllll}
\hline TBNE & & 2.4 & 3.3 & 2.5 \\
$\mathrm{HI}$ & $p=0.001^{*}$ & & 2.6 & 2.3 \\
$\mathrm{PI}$ & $p<0.001^{*}$ & $p=0.001^{*}$ & & 1.4 \\
SCP & $p=0.002^{*}$ & $p=0.003^{*}$ & $p=0.023^{*}$ & \\
& TBNE & $\mathrm{HI}$ & $\mathrm{PI}$ & SCP
\end{tabular}

(a) Asterisk $(*)$ marks statistically significant differences

(b) Interpretation effect size: $>0.2$ small; $>0.5$ medium; $>0.8$ large; $>1.2$ very large; $>2.0$ huge

Table 5 Probability of statistically significant differences and effect size of cement pairings $5 \mathrm{~mm}$ abutment height

\begin{tabular}{lllll}
\hline TBNE & & 0.3 & 2.0 & 6.2 \\
$\mathrm{HI}$ & $p=0.068$ & & 1.5 & 5.9 \\
$\mathrm{PI}$ & $p=0.004^{*}$ & $p=0.002^{*}$ & & 4.6 \\
SCP & $p<0.001^{*}$ & $p<0.001^{*}$ & $p<0.001^{*}$ & \\
& TBNE & $\mathrm{HI}$ & $\mathrm{PI}$ & $\mathrm{SCP}$
\end{tabular}

(a) Asterisk $(*)$ marks statistically significant differences

(b) Interpretation effect size: $>0.2$ small; $>0.5$ medium; $>0.8$ large; $>1.2$ very large; $>2.0$ huge

Table 6 Observed cement remnants; for codes refer to Table 2

\begin{tabular}{lllll}
\hline Cement & \multicolumn{4}{l}{ Code (modified adhesive remnant index) } \\
\cline { 2 - 5 } & Code $\mathbf{1}(\%)$ & Code $\mathbf{2}$ (\%) & Code $\mathbf{3}$ (\%) & Code $\mathbf{4}$ (\%) \\
\hline TBNE & 18.75 & 68.75 & 12.50 & 0 \\
HI & 6.25 & 6.25 & 6.25 & 81.25 \\
PI & 0 & 0 & 25 & 75 \\
SCP & 0 & 0 & 68.75 & 31.25 \\
\hline
\end{tabular}

abutment. The semi-permanent and permanent cements quantitatively rather remained on the inside of the crown after removal from the abutment. The
Table 7 Probability of statistically significant differences regarding observed cement remnants

\begin{tabular}{lllll}
\hline TBNE & & & & \\
\hline $\mathrm{HI}$ & $p<0.001^{*}$ & & & \\
$\mathrm{PI}$ & $p<0.001^{*}$ & $p=0.834$ & & \\
SCP & $p<0.001^{*}$ & $p=0.023^{*}$ & $p=0.015^{*}$ & \\
& TBNE & HI & PI & SCP
\end{tabular}

Asterisk (*) marks statistically significant differences

Kruskal-Wallis-Test shows statistically significant differences between all cements regarding their cement residues $(p<0.001)$.

Solely, no statistically significant difference was found between PI and HI (Table 7).

\section{Discussion}

Both null hypotheses stating that there is no difference in pull-off force between the chosen types of cement as well as that there is no difference in pull-off force between the abutment heights has to be rejected. Permanent implantcements presented a higher pull-off force than semi-permanent ones. However, the latter have a higher pull-off force than temporary cements. The unintended retention loss of $56.0 \%$ of the temporary cemented (TBNE) crowns was disproportionally high. With the semi-permanent methacrylate-based cement (PI), the secondhighest results of pull-off forces could be achieved but crown fractures were present. The pull-off force observed in semi-permanent methacrylate-infiltrated zinc oxide cement (HI) was high enough to avoid unintentional losses and low enough to avoid crown fractures during the removal.

This study confirmed that permanent cements (SCP) show higher pull-off forces than semi-permanent ones (like PI and HI), which in return show higher pull-off forces than temporary cements (TBNE) [14]. As shown in previous studies, temporary cements presented increased unintentional decementations [5]. Glutekin et al. [17] 
compared seven implant-cements and observed a significant difference between semi-permanent methacrylatebased cement (PI) and TBNE, which is consistent with the results of this study. Lopez et al. [19] demonstrated that resin-based cements such as PI and HI have statistically significantly higher pull-off force compared to the temporary cement group and regardless of the crown material. Silva et al. [26] observed similar results by testing zirconia crowns on titanium abutments. Due to its low solubility and high mechanical and sealing properties, resin-based semi-permanent cements are most effective in preventing microleakages [27]. This might explain the comparable but not equal results of PI and HI whose pull-off forces were less than those of the permanent cement but higher than for the provisional cement.

According to the observed cement remnants, all cements differ statistically significant from each other, except the two semi-permanent cements. Semi-permanent and permanent cement groups showed a higher affinity for the ZLS surface of the crowns than for the titanium surface of the abutments. The high adhesion of the cement residues to the crown surface of the permanent cement may be due to the previous silanization $[28,29]$. The highest pull-off forces were achieved by the permanent composite cement, and therefore the risk of damaging the restoration is increased, which is corroborated by the fractured crowns during the removal trial.

The null hypothesis that the abutment height has no relevant impact on the pull-off force has to be partially rejected. Except for the use of SCP and HI the abutment height showed no statistically significant impact on the pull-off force. Other studies showed an increasing pulloff force by increasing abutment height (from 4 to $6 \mathrm{~mm}$ ) in permanent cements, which corroborates the result of this investigation [30]. Pull-off forces of temporary and semi-permanent cements luting ZLS crowns to titanium abutments were not relevantly affected by different abutment heights in other studies [26]. Sarfaraz et al. [15] used PI and TBNE and presented comparable results examining height differences of $1.5 \mathrm{~mm}$. The abutment height has tremendous importance in everyday clinical practice and is supported by the large effect sizes in our study. Customized abutments are an existing alternative that shows a lower risk of crown loosening in comparison to stock abutments [31]. In cases of limited space customized abutments should be considered to improve retention. The combination of different surface treatment combinations of sandblasting and primer application could improve retrievability when using stock abutments [32]. Other studies observed significant differences in pull-off forces affected by abutment height when using titanium abutments and zirconia crowns or titanium abutments and cobalt-chromium crowns [33, 34].
In this study, high standard deviations were found. This phenomenon may be partially attributed to the reuse of the crowns and stock titanium abutments, which were reset manually by sandblasting and cleansing. Potentially repeated refurbishing of the stock abutment and crown surface may cause alteration in surface roughness of the titanium and ZLS surface [35, 36]. For this reason we limited the reuse of the crowns to two times. Naumova et al. [37] proved that a combination of sandblasting and repeated cementation of implantsupported cobalt-chromium crowns leads to reduced retention force independent of the luting agent. Additionally, the adjustment of the abutment heights and the closing of the screw access hole were carried out manually. In summary, it could be considered that the surfaces of each stock titanium abutment were slightly different in each test. Nonetheless, the procedure reflects a standard situation in daily dental practice.

\section{Conclusions}

For clinical purposes, it seems impossible to define the "best" cement for all implant situations. Instead, a ranking of types of cement should be sought and dependence of the abutment height should be kept in mind [21]. Due to the high number of spontaneous decementations and low pull-off forces, the use of a temporary cement for luting cannot be recommended. In cases of retention loss, clinicians can choose alternative luting agents in ascending order $[13,16]$. Based on the results made in the present investigation a ranking of implant cements can be made as follows: $\mathrm{TBNE}<\mathrm{HI}<\mathrm{PI}<\mathrm{SCP}$. However, semi-permanent cementation, here with PI and $\mathrm{HI}$, seems to be the most suitable in the case of luting ZLS crowns to stock titanium abutments, as the pull-off forces were high enough to ensure a low risk of unintended debonding and low enough for a predictable successful attempt of intended debonding. For further investigations, it would be a necessity to define the separation between temporary, semi-permanent, and permanent types of cement. Within our investigation and the limitations of this in-vitro study, the semi-permanent methacrylate-infiltrated zinc oxide cement (HI) presented as favorable for semi-permanent cementation of ZLS crowns on titanium abutments.

\section{Abbreviations \\ ZLS: Zirconia reinforced lithium silicate; iSC: Implant-supported single crowns; iFDPs: Multi-unit fixed dental prostheses; TBNE: TempBond NE ${ }^{\circledR} ; \mathrm{HI}$ : Harvard} Implant ${ }^{\circledR} ;$ PI: Premier ${ }^{\circledR}$ Implant Cement $^{\text {TM }} ;$ SCP: SpeedCEM ${ }^{\circledR}$ Plus.

Acknowledgements

Not applicable. 


\section{Authors' contributions}

LM and acquired and analyzed all data included in the present article and performed the preparation of the manuscript under the supervision of OS. AR and DR revised the work and approved the submitted version. All authors read and approved the final manuscript.

\section{Funding}

Open Access funding enabled and organized by Projekt DEAL. The work was supported by the Oral Reconstruction Foundation. We highly appreciate the work by Mrs. Francoise Peters for the logistic assistance and the substantial financial support of this project (ORF 217).

\section{Availability of data and materials}

The datasets analyzed during the current study are available from the corresponding author on reasonable request.

\section{Declarations}

\section{Ethics approval and consent to participate}

Not applicable.

\section{Consent for publication}

Not applicable.

\section{Competing interests}

The authors declare that they have no competing interests.

\section{Author details}

${ }^{1}$ Nossen, Germany. ${ }^{2}$ Department of Prosthodontics and Materials Science, University of Leipzig, Liebigstrasse 12, 04107 Leipzig, Germany. ${ }^{3}$ Department of Prosthetic Dentistry, University Medical Center Hamburg-Eppendorf, Martinistrasse 52, 20246 Hamburg, Germany.

Received: 24 July 2021 Accepted: 5 November 2021

Published online: 19 November 2021

\section{References}

1. Bains SK, Bhatia A. Assessment of outcome of dental implant therapy in different age groups-a clinico-radiographic study. Int J Res Health Allied Sci. 2019;5:1.

2. Wittneben JG, Joda T, Weber HP, Brägger U. Screw retained vs. cement retained implant-supported fixed dental prosthesis. Periodontol 2000 2017;73:1.

3. Sailer I, Mühlemann S, Zwahlen M, Hämmerle CH, Schneider D. Cemented and screw-retained implant reconstructions: a systematic review of the survival and complication rates. Clin Oral Implants Res. 2012;23:163-201.

4. Priest G. Virtual-designed and computer-milled implant abutments. J Ora Maxillofac Surg. 2005:63:22-32.

5. Chaar MS, Att W, Strub JR. Prosthetic outcome of cement-retained implant-supported fixed dental restorations: a systematic review. J Oral Rehabil. 2011;38:697-711.

6. Chee W, Jivraj S. Screw versus cemented implant supported restorations. Br Dent J. 2006;201:8.

7. Taylor TD, Agar JR. Twenty years of progress in implant prosthodontics. J Prosth Dent. 2002;88:1.

8. Glücker C, Rauch A, Hahnel S. Attitude and treatment options in implantsupported prosthetics: a survey among a cohort of German dentists. J Adv Prosthodont. 2020;12:1

9. Tsigarida A, Chochlidakis K, Fraser D, Lampraki E, Einarsdottir ER, Barmak AB, Papaspyridakos P, Ercoli C. Peri-implant diseases and biologic complications at implant-supported fixed dental prostheses in partially edentulous patients. J Prosthodont. 2020;29:429-35.

10. Hamed MT, Abdullah Mously H, Khalid Alamoudi S, Hossam Hashem AB, Hussein Naguib G. A systematic review of screw versus cement-retained fixed implant supported reconstructions. Clin Cosmet Investig Dent. 2020;12:9.
11. Ragauskaitè A, Žekonis G, Žilinskas J, Gleiznys A, Ivanauskienè E, Gleiznys $D$. The comparison of cement-and screw-retained crowns from technical and biological points of view. Stomatologija. 2017;19:44-50.

12. Okuyama JY, de Brito RB, França FMG. Aluminum oxide sandblasting of hexagonal coping and abutment: influence on retention and marginal leakage using temporary cements. Implant Dent. 2016;25:3.

13. Korsch $\mathrm{M}$, Walther W. Retrospective analysis of loosening of cementretained vs screw-retained fixed implant-supported reconstructions. Quintessence Int. 2015:46:7.

14. Pan Y, Lin C. The effect of luting agents on the retention of dental implant-supported crowns. Chang Gung Med J. 2005;28:6.

15. Sarfaraz H, Hassan A, Shenoy KK, Shetty M. An in vitro study to compare the influence of newer luting cements on retention of cement-retained implant-supported prosthesis. J Indian Prosthodont Soc. 2019;19:2.

16. Ozkir SE, Unal SM, Yurekli E, Güven S. Effects of crown retrieval on implants and the surrounding bone: a finite element analysis. J Adv Prosthodont. 2016;8:2.

17. Gultekin P, Gultekin BA, Aydin M, Yalcin S. Cement selection for implantsupported crowns fabricated with different luting space settings. J Prosthodont. 2013:22:2.

18. Schierano G, Manzella C, Menicucci G, Parrotta A, Zanetti EM, Audenino AL. In vitro standardization of two different removal devices in cemented implant prosthesis. Clin Oral Implants Res. 2016;27:8.

19. Lopes ACDO, Machado CM, Bonjardim LR, Bergamo ETP, Ramalho IS, Witek $L$, Bonfante EA. The effect of CAD/CAM crown material and cement type on retention to implant abutments. J Prosthodont. 2019;28:2.

20. Mehl C, Harder S, Steiner M, Vollrath O, Kern M. Influence of cement film thickness on the retention of implant-retained crowns. J Prosthodont. 2013:22:8.

21. Ben-Izhack G, Shely A, Koton O, Meirowitz A, Levartovsky S, Dolev E. (In-vitro comparison between closed versus open CAD/CAM systems) Comparison between closed and open CAD/CAM systems by evaluating the marginal fit of zirconia-reinforced lithium silicate ceramic crowns. Appl Sci. 2021;11:10.

22. Mansour A, Ercoli C, Graser G, Tallents R, Moss M. Comparative evaluation of casting retention using the ITI solid abutment with six cements. Clin Oral Implants Res. 2002;13:4

23. Gale MS, Darvell BW. Thermal cycling procedures for laboratory testing of dental restorations. J Dent. 1999;27:2.

24. Årtun J, Bergland S. Clinical trials with crystal growth conditioning as an alternative to acid-etch enamel pretreatment. Am J Orthod Dentofac Orthop. 1984:85:4.

25. Sawilowsky SS. New effect size rules of thumb. J Mod Appl Stat Methods. 2009;8:26.

26. Silva CE, Soares S, Machado CM, Bergamo ET, Coelho PG, Witek L, Bonfante EA. Effect of CAD/CAM abutment height and cement type on the retention of zirconia crowns. Implant Dent. 2018:27:5.

27. Farah R, Elzeky M. An in vitro comparison of marginal microleakage of four groups of temporary cements in provisional crowns. Int J Adv Res. 2015;3:3.

28. Zarone F, Di Mauro MI, Ausiello P, Ruggiero G, Sorrentino R. Current status on lithium disilicate and zirconia: a narrative review. BMC Oral Health. 2019;19:1.

29. Elsayed A, Younes F, Lehmann F, Kern M. Tensile bond strength of socalled universal primers and universal multimode adhesives to zirconia and lithium disilicate ceramics. J Adhes Dent. 2017;19:3.

30. Al Hamad KQ, Al Rashdan BA, Abu-Sitta EH. The effects of height and surface roughness of abutments and the type of cement on bond strength of cement-retained implant restorations. Clin Oral Implants Res. 2011;22:6.

31. Korsch M, Walther W. Prefabricated versus customized abutments: a retrospective analysis of loosening of cement-retained fixed implantsupported reconstructions. Int J Prosthodont. 2015;28:522-6.

32. Egoshi T, Taira $Y$, Soeno $K$, Sawase T. Effects of sandblasting, $\mathrm{H}_{2} \mathrm{SO}_{4} / \mathrm{HCl}$ etching, and phosphate primer application on bond strength of veneering resin composite to commercially pure titanium grade 4 . Dent Mater J. 2013;32:219-27.

33. Mehl C, Harder S, Shahriari A, Steiner M, Kern M. Influence of abutment height and thermocycling on retrievability of cemented implant-supported crowns. Int J Oral Maxillofac Implants. 2012;27:5. 
34. Abbo B, Razzoog ME, Vivas J, Sierraalta M. Resistance to dislodgement of zirconia copings cemented onto titanium abutments of different heights. J Prosth Dent. 2008;99:1.

35. Cao Y, Guo YY, Chen L, Han J, Tong H, Zhang B, Zhang Y. Effects of different surface treatments on bonding strength of resin cement to machined pure titanium. J Adhes Dent. 2019;21:401.

36. Rödiger M, Rinke S, Ehret-Kleinau F, Pohlmeyer F, Lange K, Bürgers R, Gersdorff N. Evaluation of removal forces of implant-supported zirconia copings depending on abutment geometry, luting agent and cleaning method during re-cementation. J Adv Prosthodont. 2014;6:233-40.
37. Naumova EA, Roth F, Geis B, Baulig C, Arnold WH, Piwowarczyk A. Influence of luting materials on the retention of cemented implant-supported crowns: an in vitro study. Materials. 2018;11:10

\section{Publisher's Note}

Springer Nature remains neutral with regard to jurisdictional claims in published maps and institutional affiliations.
Ready to submit your research? Choose BMC and benefit from:

- fast, convenient online submission

- thorough peer review by experienced researchers in your field

- rapid publication on acceptance

- support for research data, including large and complex data types

- gold Open Access which fosters wider collaboration and increased citations

- maximum visibility for your research: over $100 \mathrm{M}$ website views per year

At BMC, research is always in progress.

Learn more biomedcentral.com/submissions 